Check for updates

Cite this: RSC Adv., 2017, 7, 44026

\title{
NIR light-triggered shrinkable thermoresponsive PNVCL nanoshells for cancer theranostics $\dagger$
}

\begin{abstract}
Deepak S. Chauhan, (D) $\dot{t}^{a}$ S. Indulekha, $\dot{t}^{a}$ Rupesh Gottipalli, ${ }^{a}$ B. Pradeep K. Reddy, ${ }^{a}$ Tanmayee R. Chikate, ${ }^{a}$ Ramkrishn Gupta, ${ }^{a}$ Dushyant N. Jahagirdar, ${ }^{a}$ Rajendra Prasad, ${ }^{b}$ Abhijit De ${ }^{* c}$ and Rohit Srivastava (D) *a

For the localized treatment of a tumor in a more controlled fashion, several stimuli-responsive nanocarriers and minimally or non-invasive techniques like photothermal therapy (PTT) have emerged. However, PTT is limited to only treatment of small and superficial tumors due to the inability of NIR light to penetrate more and kill the core cells of large and deep-seated tumors. As a preliminary step towards addressing the problem, NIR light-triggered thermoresponsive theranostic nanoshell consisting of chitosan-grafted poly(N-vinyl caprolactam) as core and biocompatible gold as shell (Au PNVCL NS) are synthesized and well characterized by various techniques. PNVCL is polymerized from $N$-vinyl caprolactam using free radical polymerization method, and chitosan is grafted to raise its lower critical solution temperature (LCST) to hyperthermic temperature $\left(\sim 43^{\circ} \mathrm{C}\right)$. Surface plasmon resonant gold shell over PNVCL NPS core is assembled by ascorbic acid-driven in situ reduction. Core to shell diameter ratio is controlled to tune the peak in NIR region (750 nm). Therapeutic potential of Au PNVCL NS is determined over breast cancer cells MCF-7, while diagnostic potential is compared with the commercial contrast agentOmnipaque.
\end{abstract}

Received 7th July 2017

Accepted 22nd August 2017

DOI: $10.1039 / c 7 r a 07485 a$

rsc.li/rsc-advances neighboring and intervening normal cells also get affected due to non-localized heating. To circumvent this, photothermal therapy (PTT) has emerged for directing the heat in a more precise, targeted and efficient way. PTT seems to have no side effect and is minimally invasive in nature in which near infrared (NIR) light is used to resonate electrons of the photothermal agent for releasing the heat exploited in localized killing of cancer cells. ${ }^{7}$

There are several photothermal agents (nanoshells, nanorods, carbon nanotubes and photothermal dyes like IR-780, IR820 , ICG, etc.) that have been used to ablate the solid tumor. ${ }^{7-11}$ However, most of the photothermal dyes and PTT agents are stigmatized with disadvantages like leaching, bleaching, very low photothermal conversion efficiency, toxicity hazards, problem in body clearance, etc. ${ }^{12,13}$ To skirt these disadvantages, biocompatible and disintegrable nanostructures showing good safety profile and photothermal efficiency are being materialized for efficiently ablating the tumor. ${ }^{\mathbf{1 4 , 1 5}}$ To further knit the photothermal agents, other therapeutic and diagnostic modalities like magnetic hyperthermia, chemotherapy, X-ray, MRI, CT, NIRF, etc. are also blending up together. ${ }^{16,17}$

Few polymers and lipid-based nanoshells for triggered release of the drug during PTT also have been developed. ${ }^{\mathbf{1 8 , 1 9}}$ Poly( $N$-isopropyl acrylamide) (PNIPAM) - a thermosensitive polymer has been used in the form of hydrogel but production of small toxic amide compounds in acidic environment moderate its application..$^{20}$ In this regard, we developed NIR 
responsive nanoshells using a thermoresponsive as well as biocompatible polymer such as poly( $N$-vinyl caprolactam) (PNVCL) to harness the maximum potential of NIR lighttriggered controlled (ON-OFF) drug release without any side effect.

Thermosensitive polymer, viz. PNVCL and PNIPAM, based particles shrink and help in efficient drug release when temperature exceeds their lower critical solution temperature (LCST). ${ }^{21}$ To exploit this property, Rejinold et al. and our group have prepared thermoresponsive and biodegradable chitosangrafted PNVCL particles (loaded with 5-fluorouracil) and gel (loaded with acetamidophenol and etoricoxib) for chemotherapy and pain management, respectively. ${ }^{22,23}$ In this studies, the researchers have shown that grafting of chitosan enabled the increase in biocompatibility, biodegradability and elevated the LCST to its desired value. Moreover, they also studied the drug release behavior of the chitosan-grafted PNVCL particles by varying the temperature below and above the LCST that would be effectively used in our further report. Herein, as part of our ongoing research in cancer theranostics, ${ }^{24,25}$ we report development of in situ gold deposited thermoresponsive PNVCL nanoshells (Au PNVCL NS), as a preliminary step towards the efficient and controlled (ON-OFF) release of drugs in the core of large and deep seated tumors at NIR light-induced hyperthermic conditions (Fig. 1).

\section{Results and discussion}

Hydrophobic drugs rapidly start diffusing from the carrier as they enter the blood, which results in systemic toxicity as well as reduction in therapeutic efficacy at the targeted site. This could be minimized if stimuli-responsive stable formulations are developed. ${ }^{26}$ In this regard, thermoresponsive carboxylterminated poly $(N$-vinyl caprolactam) (PNVCL-COOH) was synthesized from $N$-vinyl caprolactam (NVCL) using free radical polymerization technique. ${ }^{23}$ However, LCST of PNVCL is $\sim 32{ }^{\circ} \mathrm{C}$, which is not suitable for hyperthermia triggered drug delivery. Hence chitosan was grafted to PNVCL-COOH with the help of a coupling agent (EDC-HCl/NHS) at various (w/w) ratios to obtain the desired lower critical solution temperature (LCST), as shown in Table 1.

It was observed that LCST around $\sim 42^{\circ} \mathrm{C}$ was obtained when chitosan to PNVCL-COOH ratio was $1: 4$ (75 $\mathrm{mg}$ of chitosan and $300 \mathrm{mg}$ of PNVCL-COOH). Chitosan grafting to PNVCL-COOH was confirmed by FTIR, similar to our previous report. ${ }^{23}$ Briefly, in PNVCL-COOH, characteristic stretching of $-\mathrm{C}=\mathrm{O}$ and $-(\mathrm{C}=\mathrm{O})-\mathrm{OH}$ group was found at $1631 \mathrm{~cm}^{-1}$ and $3474 \mathrm{~cm}^{-1}$, respectively. In chitosan and chitosan grafted PNVCL-COOH, the characteristic stretching vibrations of hydroxyl, aliphatic $\mathrm{C}-\mathrm{H}$, and acetylated amino groups were observed at $3448 \mathrm{~cm}^{-1}$ and $2925 \mathrm{~cm}^{-1}$, while characteristic stretching of amide I and $\mathrm{CN}$ bond was found at $1630 \mathrm{~cm}^{-1}$ and $2856 \mathrm{~cm}^{-1}$, respectively (Fig. S1†).

It was observed that when the temperature was below $42{ }^{\circ} \mathrm{C}$, CHT- $g$-PNVCL was completely soluble in the water, while at temperature above $42{ }^{\circ} \mathrm{C}$ hydrogel-like structure appeared (Fig. $\mathrm{S} 2 \mathrm{~A} \dagger$ ). Phase separation occurs due to increment in hydrophobic interactions among caprolactam groups via reduction in hydrogen bonding between CHT- $g$-PNVCL and water molecules. ${ }^{24}$ CHT- $g$-PNVCL NPs characterized by FEGSEM were found to have proper spherical morphology with an average diameter of around $300 \mathrm{~nm}$ (Fig. $\mathrm{S} 4 \dagger$ ).

Hyperthermia is known to affect tumor microcirculation and cause irreversible damage via protein denaturation and disassembly of protein biomolecules in the nucleus and the cytoskeleton. It also sensitizes the cancer cells for radiotherapy and chemotherapy by disrupting the membrane integrity and modifying the hydrostatic pressure. Reduction of $\mathrm{pH}$ in tumor microenvironment has also been noticed during hyperthermia due to the increase of lactic acid as well b-hydroxybutyric acid content and damaged drainage system. Acidic conditions not only support the killing of cancer cells but also inhibit the repair of damaged cells and development of thermotolerance. ${ }^{6}$ However, mild hyperthermia $\left(42-43^{\circ} \mathrm{C}\right)$ is an ineffective standalone therapy in clinical setting and mostly used as adjuvant to radio and chemotherapy. ${ }^{27}$

Although hyperthermia has long been considered as an adjuvant therapy for conventional treatments like radiotherapy and chemotherapy, the major problem is specific delivery of heat to the therapeutic region, particularly when it is deep seated and surrounded by healthy tissues. Spreading of heat via conduction, convection, and radiative transfer also affects the nearby healthy tissues. Another constraint in hyperthermiacombined radio or chemotherapy is the time compliance, that is maximum synergistic effect is observed if they are applied together or within 1-2 h of time interval. ${ }^{27}$

To address these problems, NIR light directed hyperthermia approved by FDA seems the best treatment modality for easily accessible and surface tumors (head, neck, and melanoma). NIR light has become the interest of research due to its low body scattering, enhanced irradiation, high penetration, and energy absorption, as well as minimal autofluorescence during in vivo imaging. ${ }^{28}$ There are several dyes available for the conversion of NIR light to heat, but the efficacy of nanoshells exceed them to a great extent. It has been noticed that nanoshells have absorption cross section order of magnitude of six more than conventional NIR dyes like ICG. Moreover, in molecular dyes, absorption depends on the transition of molecular orbital electrons, while in the nanoshell it is affected by the rigidity of the metallic structure which makes them robust from photobleaching commonly seen in NIR dyes. ${ }^{29}$

In this regard, CHT- $g$-PNVCL NPs were gold coated in situ with the help of ascorbic acid and tuned to absorb the light in NIR region by varying chloroauric acid concentrations ranging from 1 to $5 \mathrm{mM}$ (Fig. 2A). It was observed that absorbance peak showed a red shift with the increase of chloroauric acid concentration. At $4 \mathrm{mM}$ of chloroauric acid, absorbance peak shifted to $\sim 750 \mathrm{~nm}$, and it remained consistent even after the reaction was scaled up to 10 times (Fig. 2A and B). However, at $5 \mathrm{mM}$ of the chloroauric acid, the peak was blue shifted instead of showing a red shift. It is assumed that excess amount of gold favored the synthesis of free gold nanoparticles rather than being deposited over CHT- $g$-PNVCL NPs. Formation of a gold shell around CHT- $g$-PNVCL NPs was indicated by the 


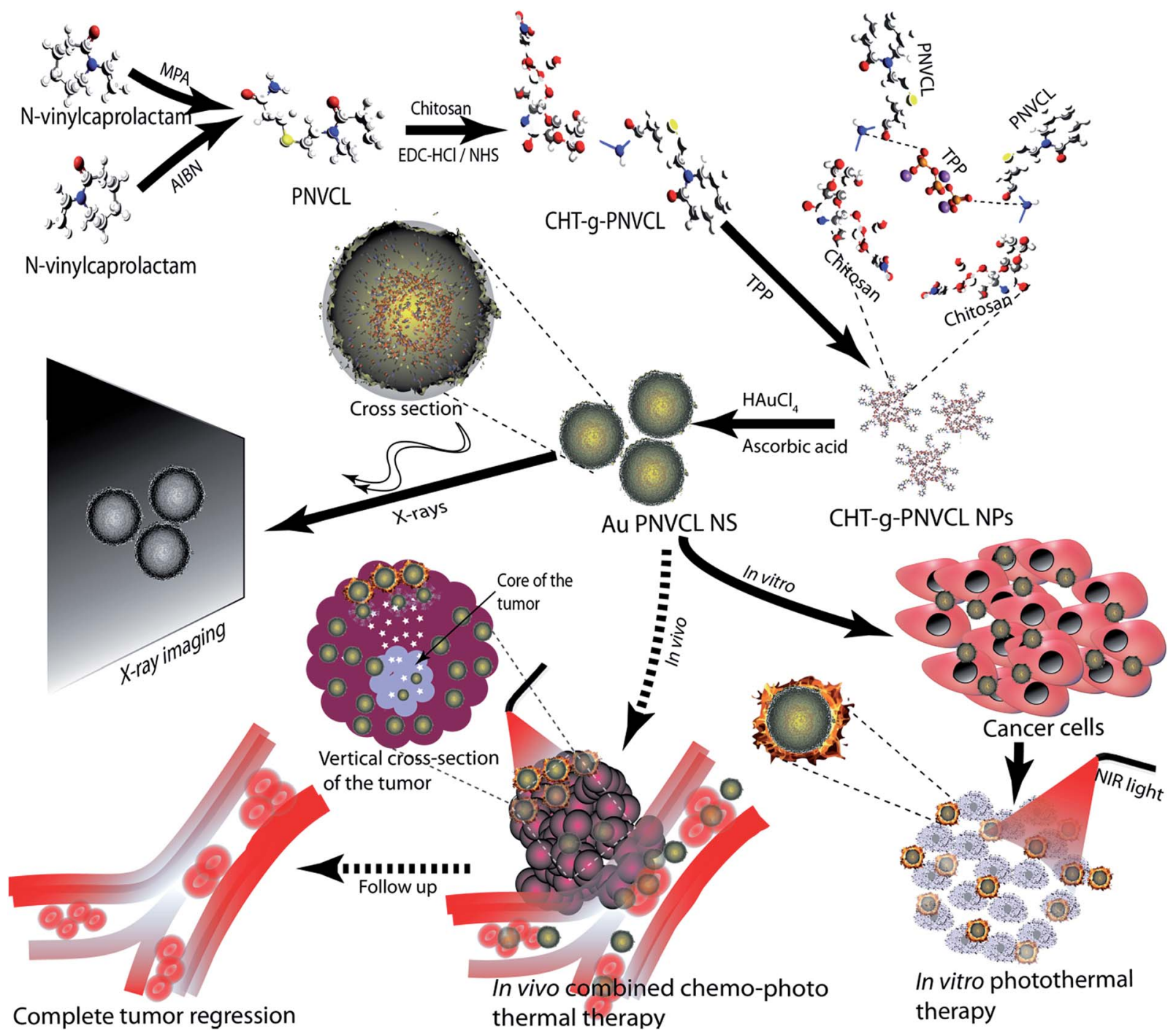

Fig. 1 Illustration showing synthesis and theranostic nature of Au PNVCL NS. Dashed arrows represent future perspective.

Table 1 LCST of CHT-g-PNVCL obtained on trying different $w / w$ ratio of chitosan and PNVCL

\begin{tabular}{ll}
\hline Chitosan : PNVCL $(\mathrm{w} / \mathrm{w})$ & LCST $\left({ }^{\circ} \mathrm{C}\right)$ \\
\hline $0: 1$ & 32 \\
$1: 0.5$ & $33 \pm 1.1$ \\
$1: 1$ & $35 \pm 0.2$ \\
$1: 2$ & $38 \pm 0.1$ \\
$1: 3$ & $40.1 \pm 0.2$ \\
$1: 4$ & $42.2 \pm 1.2$
\end{tabular}

appearance of bluish green color from colorless solution (Fig. S2B $\dagger$ ). Zeta potential of Au PNVCL NS changed to $+13 \pm$ $1.4 \mathrm{mV}$ from $-8 \pm 1.7 \mathrm{mV}$, which also establishes the masking of negatively charged functional groups on the surface of CHT$g$-PNVCL NPs by the gold layer.

To understand the increment in temperature upon $750 \mathrm{~nm}$ laser irradiation, phototransduction experiment was performed.
Au PNVCL NS along with controls (water and CHT- $g$-PNVCL NPs) was kept widely separated in 96-well plate maintained at $37^{\circ} \mathrm{C}$. It was observed that when the laser was irradiated over Au PNVCL $\mathrm{NS}$, temperature incremented from $37^{\circ} \mathrm{C}$ to $49^{\circ} \mathrm{C}$ within $2 \mathrm{~min}$, and after that it remained nearly constant for $5 \mathrm{~min}$. However, on further irradiation, it started decreasing due to damage of particles (established in further studies) and heat dissipation. However, in controls, temperature did not exceed $38.5^{\circ} \mathrm{C}$, even at the end of $7 \mathrm{~min}$ of laser irradiation (Fig. 3).

Furthermore, to determine the photothermal efficiency $(\eta)$ of Au PNVCL NS, following equation was used ${ }^{30}$

$$
\eta=\frac{h S\left(T_{\max }-T_{\text {surr }}\right)-Q_{\mathrm{dis}}}{I\left(1-10^{-A_{750}}\right)}
$$

where heat transfer coefficient $(h S)$ was found to be $3.81 \mathrm{~mW}$. The difference between maximum temperature $\left(T_{\max }\right)$ attained by the Au PNVCL NS and room temperature $\left(T_{\text {surr }}\right)$ was found to be $20.6{ }^{\circ} \mathrm{C}$. Baseline energy input $\left(Q_{\text {dis }}\right)$, laser power $(I)$, and the absorbance of $\mathrm{Au}$ PNVCL NS at $750 \mathrm{~nm}\left(A_{750}\right)$ were determined 

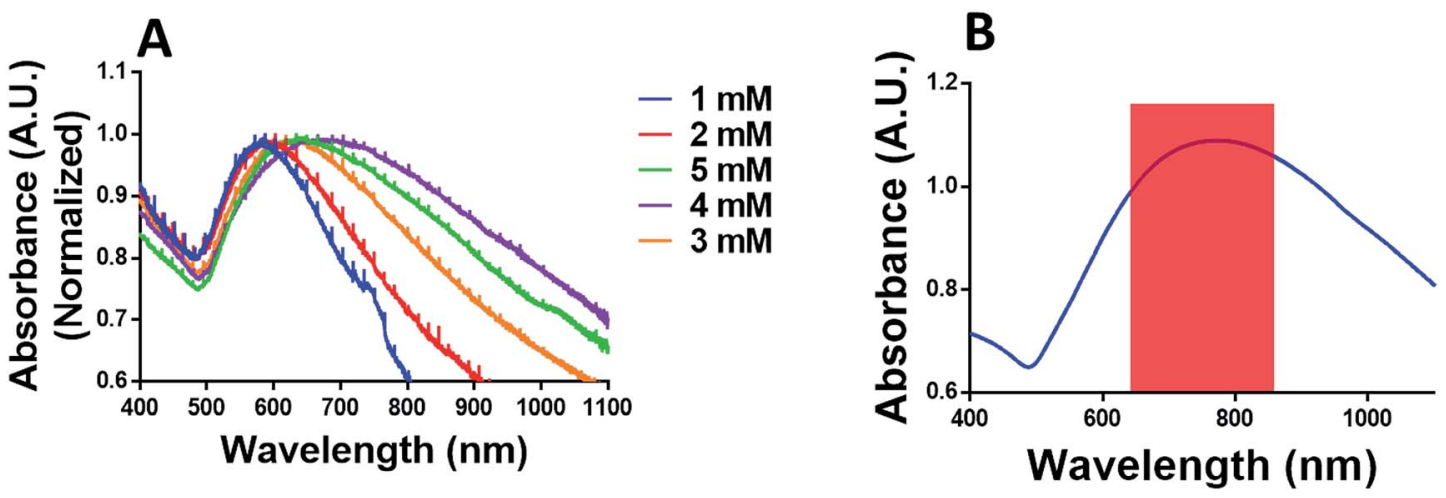

Fig. 2 Absorbance of Au PNVCL NS. (A) Shift in Au PNVCL NS absorbance during peak tuning in NIR region (750 nm) using different conc. of $\mathrm{HAuCl}_{4}$. (B) Au PNVCL NS absorbance after scaling up the synthesis to 10 times.

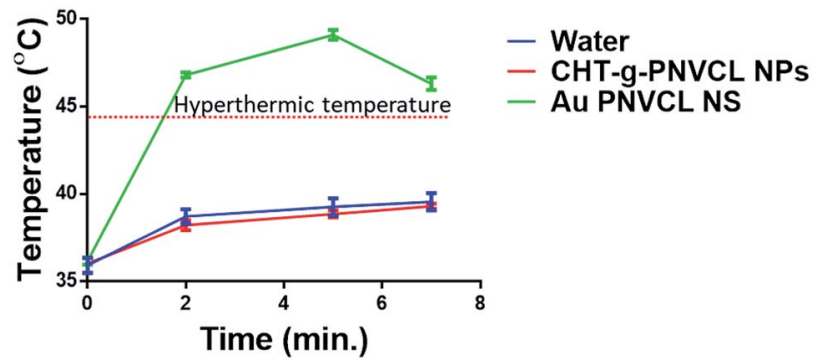

Fig. 3 Temperature increment in response to laser irradiation over $\mathrm{Au}$ PNVCL NS, CHT-g-PNVCL NPs and water.

to be $8.1 \mathrm{~mW}, 650 \mathrm{~mW}$ and 0.2544 , respectively. Thus, the photothermal transduction efficiency $(\eta)$ of Au PNVCL NS turned out to be $24.42 \%$. Detailed calculation is provided in ESI and Fig. S3. $\dagger$

It has been experienced in several studies that repetitive dosage of photothermal therapy may be required for the complete tumor ablation. For the same, photothermal agents need to be retained in tumor for longer time, and this is facilitated if the surface of particles is textured. Surface morphology of $\mathrm{Au}$ PNVCL NS was found to be ruffled on the surface, and lattice fringes confirmed the presence of the gold shell over the CHT- $g$-PNVCL NPs. In addition, gold coating was also validated from EDAX (energy dispersive X-ray spectrometer) analysis and SAED (surface area electron diffraction) pattern (Fig. 4A-G).

The biocompatibility of the nanohybrid is a matter of concern for any in vivo application. Although PNVCL and gold are biocompatible, we assessed the potential toxicity of assynthesized $\mathrm{Au}$ PNVCL NS at thrice the therapeutic dosage over mouse normal fibroblast L929 using 24 h MTT assay. As expected, Au PNVCL NS did not show any toxicity even at thrice the therapeutic conc. i.e. $650 \mu \mathrm{g} \mathrm{mL}^{-1}$ (Fig. 5A). Cells were also found to be morphologically intact and well spread. Growth density of formazan crystals determined by light microscope was also found similar to that of negative control (Fig. 5B).

There has been a development of several dual (chemophotothermal) therapeutic nanohybrids e.g. drug loaded or conjugated nanospheres, half-shell nanoparticles, and graphene oxides. ${ }^{31-35}$ PTT acts as chemo and radiosensitizer by disrupting the membrane integrity to improve the drug uptake. It helps in reducing the therapeutic dosage of drug as well the laser intensity required. ${ }^{36}$

Higher dosage of anticancer drugs causes systemic toxicity due to lack of specificity and inefficient accumulation to the desired organ, while high laser intensity chars dark color skin. ${ }^{36}$ There seems no report of combining self-sufficient thermoresponsive photothermal agents with chemotherapy to further reduce the therapeutic dosage of drug and laser intensity. In this regard, highly efficacious thermoresponsive Au PNVCL NS was developed and its potential to deliver standalone PTT was determined both quantitatively and qualitatively over human breast cancer cell line MCF-7. It was found that $90 \%$ of cancer cells died within 4 min of irradiation with $750 \mathrm{~nm} \mathrm{CW}$ laser with a power density of $1.76 \mathrm{~W} \mathrm{~cm}^{-2}$. While in controls (cells, cells + laser, cells + Au PNVCL NS) cell viability remained above 90\% (Fig. 5C). Photoablation potential of Au PNVCL NS was also determined qualitatively by staining cells with propidium iodide. It was seen that a number of dead cells (identified as red dots) in wells subjected to photothermal treatment (cells $+\mathrm{Au}$ PNVCL NS + laser) were in very large numbers in comparison to controls (Fig. 6, S5†).

Thus, NIR-responsive Au PNVCL NS not only delivered standalone and spatially controlled photothermal therapy but also devised a way to combine the other treatment modalities like radiotherapy or chemotherapy for the better treatment of large and deep-seated tumors with reduced risk of systemic toxicities and skin (dark) damage.

Although photothermal therapy seems very promising and minimal invasive for the treatment of superficial solid tumor, it suffers from a few limitations like the intensity of NIR light (800 $\mathrm{nm}$ ) reduces to $10 \%$ after $2 \mathrm{~cm}$ of tissue penetration due to scattering from the tissue and absorption by the intervening nanoshells. It limits the damage depth in nanoshell-mediated thermal therapy similar to conventional hyperthermia...$^{27,37}$ Condition worsens further if low efficacious photothermal agents are used.

Various groups have shown successful remission of tumor in mice model using different chemo-photothermal agents like nanoshells, nanorods, carbon nanotubes, etc. At a power 

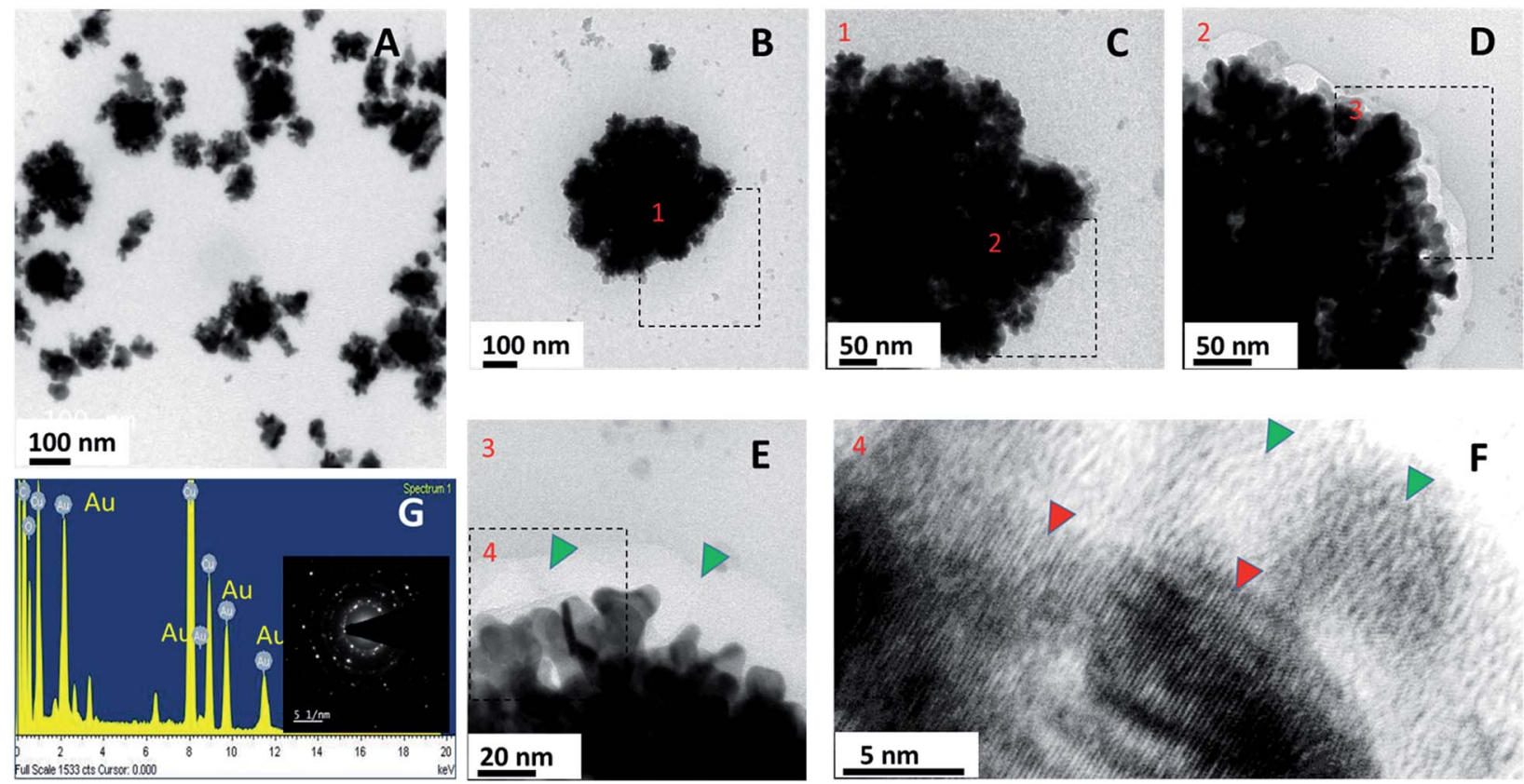

Fig. 4 Optical and elemental characterization of Au PNVCL NS. (A-F) FEG-TEM images of Au PNVCL NS at different magnifications showing ruffled morphology and lattice fringes of gold shell on the edges; green triangles indicate PNVCL and red one gold's lattice fringes. (G) Elemental analysis along with diffraction pattern (inset) of Au PNVCL NS confirms gold deposition over PNVCL core.
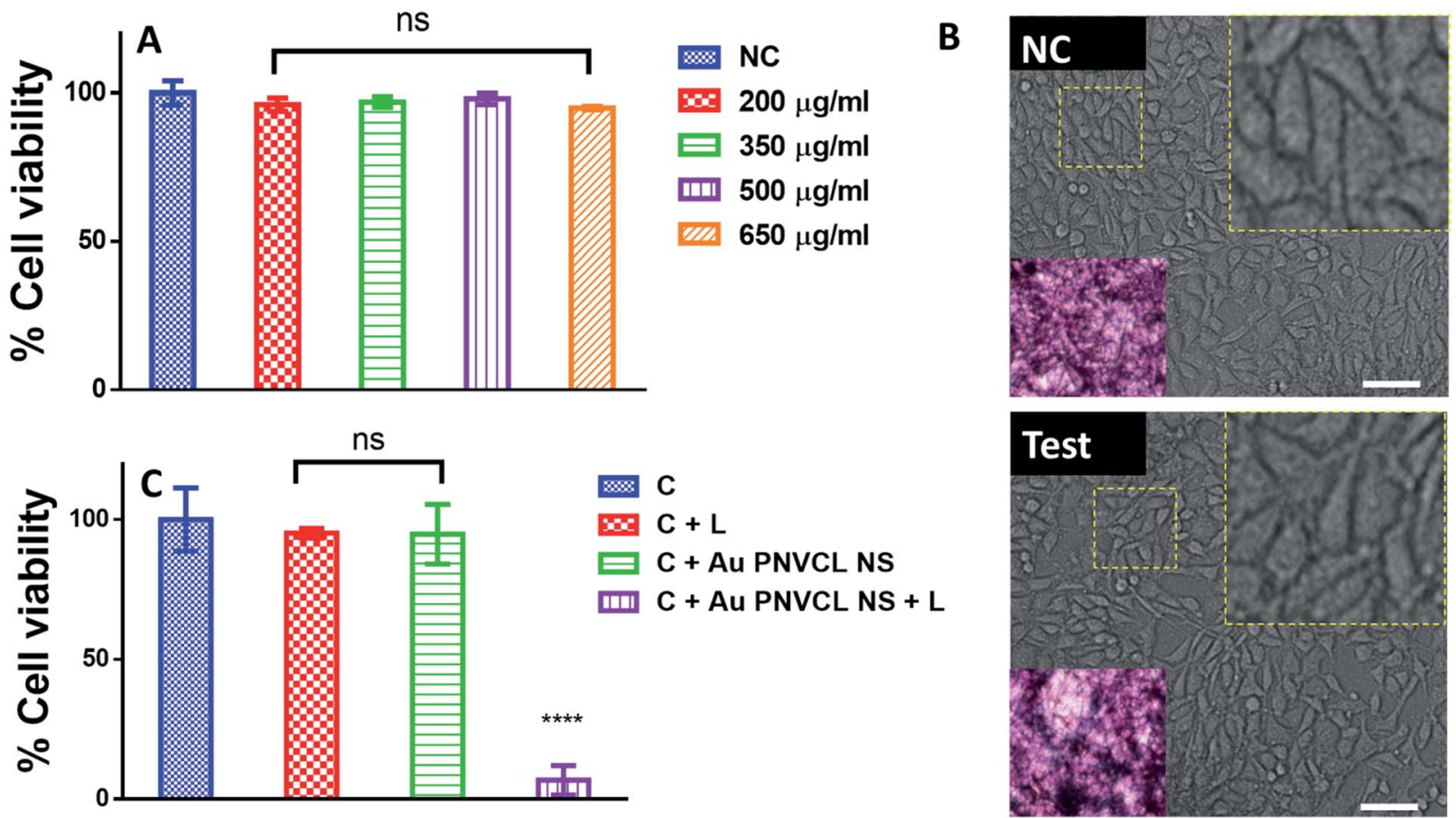

Fig. 5 In vitro biocompatibility test and photothermal therapy using MTT assay. (A) Percentage viability of L929 cells obtained after $24 \mathrm{~h}$ incubation with different concentrations of Au PNVCL NS. (B) Optical microscopic images of negative control (NC)-L929 cells without treatment and test-L929 cells incubated with $650 \mu \mathrm{g} \mathrm{mL}^{-1}$ of Au PNVCL; insets showing proper spindle shaped morphology of cells (zoom factor 7 ) and density of MTT crystals. (C) Quantitative analysis of in vitro photothermal therapy over breast cancer cell line MCF-7. Abbreviations-C: cells, C + L: cells + laser, C + Au PNVCL NS: cells incubated with Au PNVCL NS, and C + Au PNVCL NS + L: 4 min laser irradiation over cells incubated with Au PNVCL NS, $(* * * p<0.0001$ significantly different).

density of around $4 \mathrm{~W} \mathrm{~cm}^{-2}$. Usually, 4-6 $\mathrm{mm}$ of damage depth is observed but there is also a report of $1 \mathrm{~cm}$ in some studies using high laser power intensity. ${ }^{38}$
To determine the potential of Au PNVCL NS for delivering the drug to the core of the large and deep seated tumor using low power NIR light-triggered shrinkage led disintegration, Au 

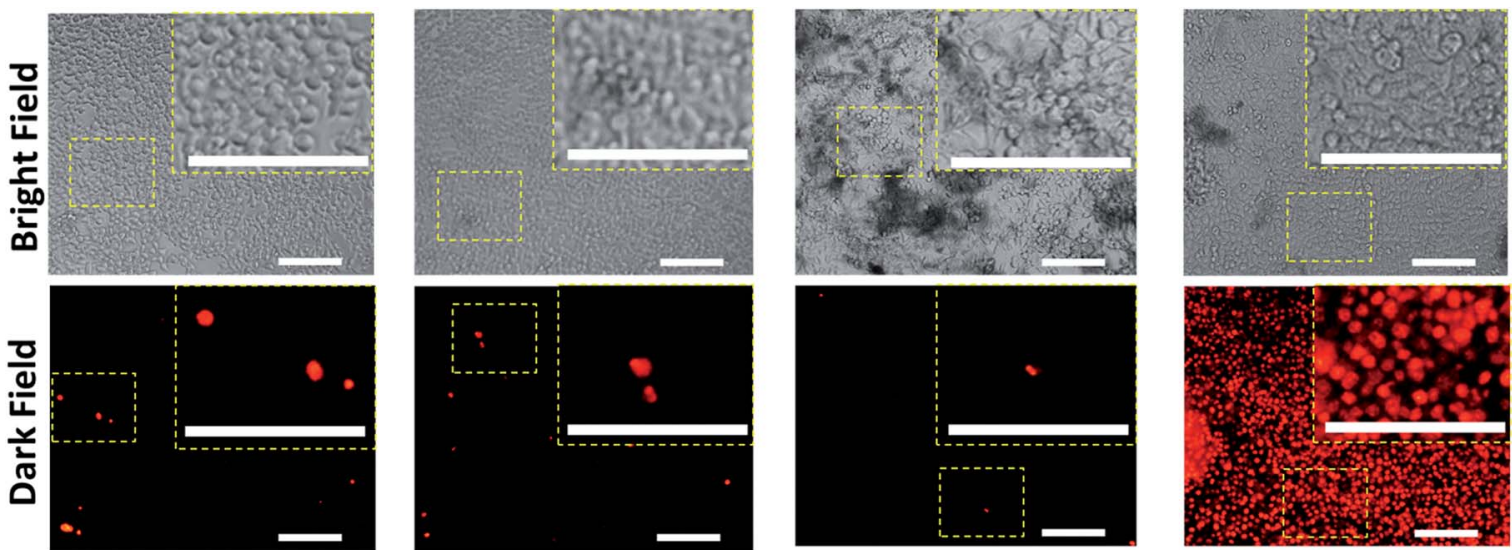

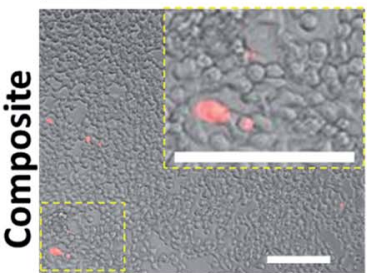

C

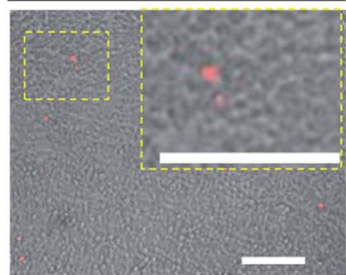

$\mathrm{C}+\mathrm{L}$

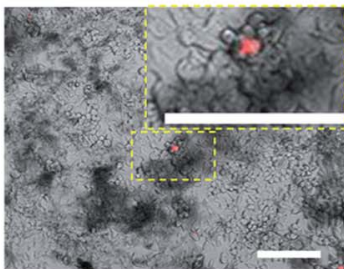

C + Au PNVCL NS

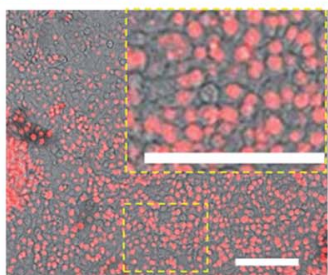

$\mathrm{C}+\mathrm{Au}$ PNVCL NS + L

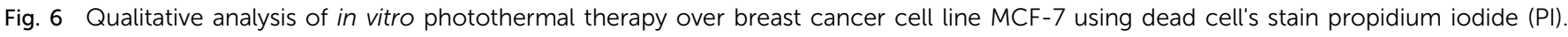

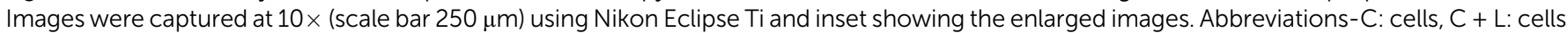

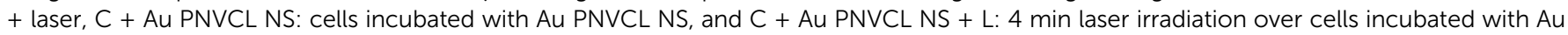
PNVCL NS.

PNVCL NS was irradiated for different time periods, and samples were analyzed using FEG-TEM and UV-Vis-NIR spectroscopy. It was found that Au PNVCL NS shrunk to a great extent, and the extent of shrinkage was related to the duration of laser irradiation (Fig. 7A). It also corroborates our previous finding of efficacious drug release from thermoresponsive polymer gel. ${ }^{23}$ PNVCL being the thermoresponsive polymer, the rationale of efficacious triggered release at hyperthermic conditions is well justified. The absorbance of Au PNVCL NS was also decremented with the time of laser irradiation; this indicated that the disturbance in gold shell structure was due to NIR light driven shrinkage led disintegration (Fig. 7B).

These results indicate that chemo-photothermal treatment of deep-seated large tumors is feasible using shrinkage led disintegration of drug loaded Au PNVCL NS at low power setting. Moreover, thermoresponsive Au PNVCL NS will positively help in efficient and controlled (ON-OFF) release of drug corresponding to laser irradiation (Fig. 7C).

There are several iodine and barium sulfate based CT contrast agents. However nanoparticles-based multifunctional contrast agents have achieved prominence due to their complementary advantages. Development of nanoparticlesbased contrast agents is also emphasized due to their longer vascular half-life than the molecular contrast agents $e . g$. iodine encapsulated liposomes. It gives benefit of long time monitoring and makes imaging more convenient and patient friendly. ${ }^{39,40}$

Iodine-based contrast agents are used daily in clinics for CT imaging. However their rapid pharmacokinetics and viscosity of injectable solution handicap its potential. Studies suggest that gold proved to be a better contrast agent than iodine due to the ability to attenuate more amount of X-rays, biocompatibility, and higher absorption coefficient (5.16 and $1.94 \mathrm{~cm}^{2} \mathrm{~g}^{-1}$ ). Its bio-inertness and easily conjugating surface to targeting moiety gives several fold advantages over quantum dots and fluorescence dyes, which have inherent limitations for in vivo applications. $^{\mathbf{4 0 , 4 1}}$

To determine the feasibility of Au PNVCL NS as CT contrast agents, samples were imaged using clinical X-ray imaging scanner (Siemens) at tube voltage of $44 \mathrm{kVp}$ (commonly used for human abdomen imaging). It was observed that the contrast given by $1.5 \mathrm{mg}$ of Au PNVCL NS was far greater than that given by $100 \mu \mathrm{L}$ of water and was comparative to that of $5 \mathrm{mg}$ of commercially available iodine based contrast agent-Omnipaque (Fig. S6†). The contrast observed well corresponded to the gold's 1.6 times more X-ray attenuation potential than iodine. It is attributed to the higher atomic number and electron density of gold in comparison to iodine $\left(79,19.32 \mathrm{~g} \mathrm{~cm}^{-3} ; 53,4.9 \mathrm{~g} \mathrm{~cm}^{-3}\right) .{ }^{42}$

Iodinated contrast agents are usually injected at a conc. of $300 \mathrm{mg} \mathrm{L}^{-1}$ to achieve blood conc. of $1 \mathrm{mg} \mathrm{mL}^{-1} \cdot{ }^{43}$ However, the same enhancement could be easily obtained at a very less conc. in case of targeted Au PNVCL NS, which also builds up over time at the targeted site.

Thus, in lieu of iodine and barium sulfate based CT contrast agent, we propose disintegrable theranostic nanoprobe $\mathrm{Au}$ PNVCL NS as the biocompatible contrast agent complemented with photothermal therapy. CT based image guided photothermal therapy also helps in determining the right amount of dosage in the therapeutic site and precisely delineating the zone 
A.i

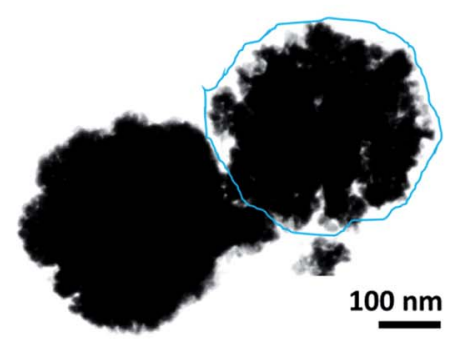

ii

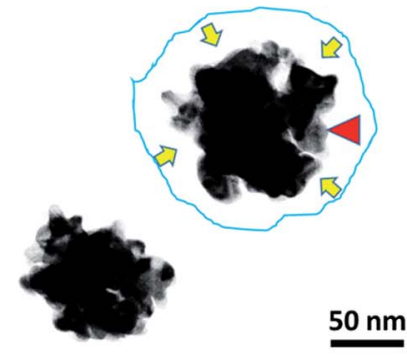

B

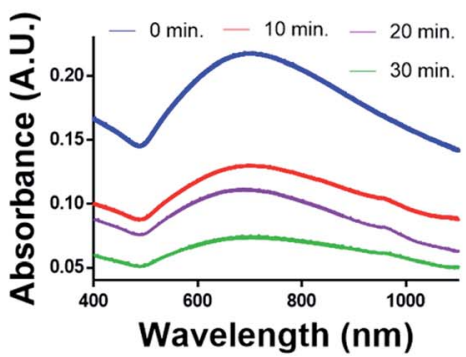

iii

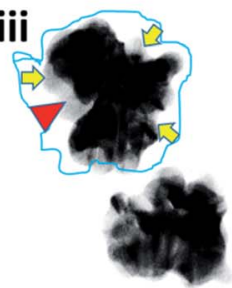

$50 \mathrm{~nm}$

C NIRLaser

ON OFF ON OFF ON OFF ON

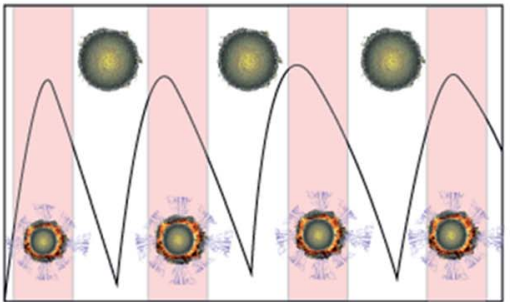

iv

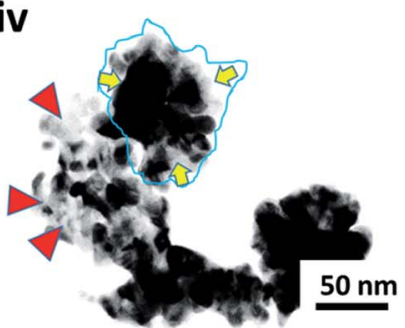

Fig. 7 NIR light triggered shrinkage led disintegration, effect over absorbance and future perspective of Au PNVCL NS. (A) (i-iv) High contrast TEM images of Au PNVCL NS irradiated for the time period of 0 min (i), 10 min (ii), 20 min (iii), 30 min (iv) showing shrinkage lead disintegration; yellow arrows indicate the shrinkage while red triangles show the PNVCL rubble. (B) Decrement in Au PNVCL NS absorbance as the laser irradiation time increased. (C) Future perspective of controlled (ON-OFF) drug release corresponding to laser irradiation.

of laser irradiation. Moreover, recent studies show that X-rays irradiation of tumor, following gold nanoparticles administration, aids in tumor regression. In this regard, Au PNVCL NS also exhibited a prospect of image-guided triple therapy (i.e. photothermal, chemo, and radiotherapy).

\section{Conclusions}

NIR light-triggered thermoresponsive $\mathrm{Au}$ PNVCL NS was synthesized by ascorbic acid-driven in situ gold coating of CHT$g$-PNVCL NPs. It was found to be spherical, segregated and having ruffled morphology on the surface. Its absorbance peak was tuned in the NIR region for its application in PTT and hyperthermia-triggered shrinkage for controlled (ON-OFF) and efficacious drug release to the core of large and deep-seated tumors. In addition, Au PNVCL NS showed superiority over Omnipaque in X-ray imaging. Considering the above findings, $\mathrm{Au}$ PNVCL NS could be considered as a promising multifunctional theranostic agent for image-guided PTT and also justify its stride for efficacious triggered release of drugs for entrenching in the core of large and deep-seated tumors in our future explorations of combined chemo-photothermal therapy.

\section{Experimental}

\section{Materials}

Chitosan (low molecular weight), $N$-vinyl caprolactam (NVCL), 2,2' azo-bis-isobutyronitrile (AIBN), 1-ethyl-3-(3dimethylaminopropyl) carbodiimide (EDC-HCl), $N$-hydroxysuccinimide (NHS), penta sodium tripolyphosphate (TPP), 3mercaptopropionic acid (MPA) and L-ascorbic acid were purchased from Sigma-Aldrich (India). Chloroauric acid $\left(\mathrm{HAuCl}_{4} \cdot 3 \mathrm{H}_{2} \mathrm{O}\right)$ was purchased from Spectrochem (India). Cellulose dialysis membrane was purchased from Himedia (India). Dulbecco's Modified Eagle Medium (DMEM), fetal bovine serum (FBS), 3-(4,5-dimethylthiazol-2-yl)-2,5diphenyltetrazolium (MTT), phosphate-buffered saline (PBS), antibiotic-antimycotic were purchased from HiMedia Laboratories Pvt. Ltd (India). High purity water from Millipore Milli-Q Gradient (USA) was used in all the preparations. All glassware were cleaned with freshly prepared aqua regia and rinsed with water before use.

\section{Synthesis of carboxyl-terminated poly $(N$-vinyl caprolactam $)$ (PNVCL-COOH)}

PNVCL-COOH was synthesized by free radical polymerization in isopropanol medium as reported in our previous studies. ${ }^{23}$ In brief, $N$-vinyl caprolactam (NVCL), MPA and AIBN were dissolved in isopropanol and left to react at $\sim 80{ }^{\circ} \mathrm{C}$ for nearly $8 \mathrm{~h}$ under inert atmosphere. An excess amount of diethyl ether was added to precipitate the product. After that, it was dried under vacuum, dispersed in $30 \mathrm{~mL}$ of Milli-Q water and then dialyzed against water for 3-4 days to remove impurities or any unreacted materials. Dialyzed product was lyophilized and stored at $4{ }^{\circ} \mathrm{C}$.

\section{Synthesis of chitosan-grafted poly( $N$-vinyl caprolactam)}

PNVCL-COOH was added to chitosan solution prepared in $(0.5 \%)$ acetic acid solution under moderate stirring. After that, coupling agent EDC-HCl/NHS in $2: 1$ weight ratio was added to the reaction mixture dropwise in dark conditions. The reaction 
was continued for about $12 \mathrm{~h}$ at room temperature under very low stirring speed for the synthesis of chitosan-grafted poly $(\mathrm{N}$ vinyl caprolactam). PNVCL-COOH was added to chitosan in different weight ratios to obtain the desired lower critical solution temperature (LCST). It was dialyzed for 3 days against water before lyophilizing and storing at $4{ }^{\circ} \mathrm{C}$.

\section{Synthesis of chitosan- $g$-PNVCL nanoparticles (CHT-g-PNVCL NPs) using TPP as the crosslinker}

CHT- $g$-PNVCL was dissolved in $0.5 \%$ acetic acid solution under moderate stirring. TPP was added resulting in the formation of nanoparticles. CHT-g-PNVCL NPs formed were centrifuged at $15000 \mathrm{rpm}$ for $30 \mathrm{~min}$ and washed several times with Milli-Q water before storing at $4{ }^{\circ} \mathrm{C}$.

\section{Preparation of gold deposited poly( $N$-vinyl caprolactam $)$ nanoshells (Au PNVCL NS)}

Herein, $100 \mu \mathrm{L}$ of $4 \mathrm{mM}$ chloroauric acid was added to $400 \mu \mathrm{L}$ of CHT- $g$-PNVCL NPs. After vortexing, $400 \mu \mathrm{L}$ of $40 \mathrm{mM}$ freshly prepared ascorbic acid was added. Au PNVCL NS was centrifuged at $10000 \mathrm{rpm}$ for $10 \mathrm{~min}$ and washed 3 times with Milli-Q water before storing at $4{ }^{\circ} \mathrm{C}$.

\section{NIR light induced thermal response}

Phototransduction was performed using $750 \mathrm{~nm}$ continuous wave $(\mathrm{CW})$ NIR laser of power density $1.76 \mathrm{~W} \mathrm{~cm}^{-2}$. The experiment was set up in a 96-well plate maintained at $37^{\circ} \mathrm{C}$. Furthermore, $100 \mu \mathrm{L}$ of $200 \mu \mathrm{g} \mathrm{mL}{ }^{-1}$ of Au PNVCL NS and controls (water, and CHT- $g$-PNVCL NPs) were added in triplicates in widely separated wells to avoid heat exchange. The laser was irradiated up to $7 \mathrm{~min}$ and the increment in temperature was noted at $0 \mathrm{~min}, 2 \mathrm{~min}, 5 \mathrm{~min}$ and $7 \mathrm{~min}$ using digital probe thermometer (MultiTex Corp, Mumbai).

Photothermal efficiency $(\eta)$ of Au PNVCL NS was determined using the following equation. ${ }^{30}$

$$
\eta=\frac{h S\left(T_{\max }-T_{\text {surr }}\right)-Q_{\text {dis }}}{I\left(1-10^{-A_{750}}\right)}
$$

where $h$ is the heat transfer coefficient, $S$ is the sample well surface area, $T_{\max }$ is the steady state maximum temperature attained by Au PNVCL NS, $T_{\text {surr }}$ is the room temperature, $Q_{\text {dis }}$ is baseline energy input, $I$ is the laser power, and $A_{750}$ is the absorbance of Au PNVCL NS at $750 \mathrm{~nm}$.

\section{In vitro biocompatibility test}

In vitro biocompatibility test was performed over mouse normal fibroblast L929 cells (procured from NCCS, Pune) using $24 \mathrm{~h}$ MTT Assay. L929 cells were seeded at a density of $\sim 10000$ cells per well in a 96-well flat bottom plate. It was incubated overnight in the incubator maintained at $37{ }^{\circ} \mathrm{C}$ and $5 \% \mathrm{CO}_{2}$. Next day, wells were washed off with the phosphate-buffered saline (PBS), and $100 \mu \mathrm{L}$ of Au PNVCL NS in conc. range of $200 \mu \mathrm{g} \mathrm{mL}^{-1}$ to $650 \mu \mathrm{g} \mathrm{mL} \mathrm{m}^{-1}$ was added in triplicates. After $24 \mathrm{~h}$, wells were washed with PBS, and $100 \mu \mathrm{L}$ media containing $10 \%$ MTT dye was added. After $4 \mathrm{~h}$ of incubation, wells were checked under a microscope for the formation of formazan crystals before addition of $200 \mu \mathrm{L}$ DMSO. Optical density was measured at wavelengths of $570 \mathrm{~nm}$ and $690 \mathrm{~nm}$ using Tecan Infinite 200 PRO plate reader. Percentage cell viability was calculated with respect to the untreated cells i.e. negative control (assumed as $100 \%$ viable) using the following equation.

$$
\% \text { cell viability }=\frac{\text { optical density of treated cells }}{\text { optical density of untreated cells }} \times 100
$$

\section{In vitro photothermal therapy (PTT)}

Quantitative photothermal assessment was performed with the help of MTT assay over human breast adenocarcinoma cells MCF-7 (procured from NCCS, Pune). MCF-7 cells were seeded at a density of $\sim 100000$ cells per well in a 96-well plate and left for overnight incubation at $37{ }^{\circ} \mathrm{C}$ and $5 \% \mathrm{CO}_{2}$. Next day, wells were washed off with PBS, and $200 \mu \mathrm{g} \mathrm{mL} \mathrm{mL}^{-1}$ Au PNVCL NS dispersed in media was added in triplicates. Furthermore, 4 min irradiation with $750 \mathrm{~nm}$ laser of power density $1.76 \mathrm{~W} \mathrm{~cm}^{-2}$ was performed. The plate was placed back in the incubator and after $24 \mathrm{~h}$, wells were washed with PBS, and $100 \mu \mathrm{L}$ media containing $10 \%$ MTT dye were added. After $4 \mathrm{~h}, 200 \mu \mathrm{L}$ of DMSO was added to each well, and optical density was measured at wavelengths of $570 \mathrm{~nm}$ and $690 \mathrm{~nm}$ using Tecan Infinite 200 PRO plate reader. Percentage cell viability was calculated as described above. For qualitative assessment, the procedure was similar to the quantitative one except that propidium iodide was added instead of MTT dye to stain dead cells. After $15 \mathrm{~min}$ of propidium iodide addition, cells were imaged in the dark and bright field by Nikon Ti Eclipse fluorescence microscope at excitation 493 and emission - $636 \mathrm{~nm}$.

\section{Shrinkage led disintegration}

NIR light-triggered shrinkage led disintegration of Au PNVCL NS was determined by placing $100 \mu \mathrm{L}$ of $200 \mu \mathrm{g} \mathrm{mL}^{-1}$ of sample in 96 well plate maintained at $37^{\circ} \mathrm{C}$. It was subjected to $750 \mathrm{~nm}$ laser irradiation for different time periods e.g. $0 \mathrm{~min}, 10 \mathrm{~min}$, $20 \mathrm{~min}$, and $30 \mathrm{~min}$. Samples were collected and analyzed by FEG-TEM and UV-Vis-NIR spectroscopy.

\section{X-ray imaging}

Comparative X-ray imaging of Au PNVCL NS, water, and commercially available iodine based contrast agent-Omnipaque was performed. Au PNVCL NS (1.5 mg), iodine (5 mg), Milli-Q water $(100 \mu \mathrm{L})$ were kept in Eppendorf plastic vials and exposed to X-rays using Siemens Digital X-ray machine at a power setting of $44 \mathrm{kVp}$. Exact gray values were determined by plot profiling the X-ray image using ImageJ.

\section{Statistical analysis}

Data are presented as mean \pm standard deviation. Statistical analysis was performed using Student's $t$-test and one-way analysis of variance (ANOVA), where $p<0.05$ was considered to be statistically significant. 


\section{Conflicts of interest}

Authors declare no conflict of interest and have approved final version of manuscript.

\section{Acknowledgements}

We are deeply appreciative of the Department of Biotechnology (DBT) grant (BT/PR14703/NNT/28/903/2015) and Indian Institute of Technology, Bombay (IIT-B) Healthcare Initiative for supporting the project. We are also very grateful to Sophisticated Analytical Instrument Facility (SAIF-IIT Bombay) for characterization of nanomaterials and to lab mates for their help in various experiments.

\section{References}

1 A. Jemal, F. Bray, M. M. Center, J. Ferlay, E. Ward and D. Forman, Ca-Cancer J. Clin., 2011, 61, 69-90.

2 K. K. Collins, Y. Liu, M. Schootman, R. Aft, Y. Yan, G. Dean, M. Eilers and D. B. Jeffe, Breast Cancer Res. Treat., 2011, 126, 167-176.

3 A. Coates, S. Abraham, S. B. Kaye, T. Sowerbutts, C. Frewin, R. M. Fox and M. H. N. Tattersall, Eur. J. Cancer Clin. Oncol., 1983, 19, 203-208.

4 K. Sjövall, G. Strömbeck, A. Löfgren, P.-O. Bendahl and B. Gunnars, Eur. J. Oncol. Nurs., 2010, 14, 147-153.

5 R. Prasad, S. Aiyer, D. S. Chauhan, R. Srivastava and K. Selvaraj, Nanoscale, 2016, 8, 4537-4546.

6 B. Emami and C. W. Song, Int. J. Radiat. Oncol., 1984, 10, 289-295.

7 W. Il Choi, A. Sahu, Y. H. Kim and G. Tae, Ann. Biomed. Eng., 2012, 40, 534-546.

8 A. M. Gobin, M. H. Lee, N. J. Halas, W. D. James, R. A. Drezek and J. L. West, Nano Lett., 2007, 7, 1929-1934.

9 H. K. Moon, S. H. Lee and H. C. Choi, ACS Nano, 2009, 3, 3707-3713.

10 C. Yue, P. Liu, M. Zheng, P. Zhao, Y. Wang, Y. Ma and L. Cai, Biomaterials, 2013, 34, 6853-6861.

11 P. Kumar and R. Srivastava, Mater. Sci. Eng., C, 2015, 57, 321327.

12 G. Fu, W. Liu, S. Feng and X. Yue, Chem. Commun., 2012, 48, 11567-11569.

13 M. D. Senarath-Yapa and S. Scott Saavedra, Anal. Chim. Acta, 2001, 432, 89-94.

14 F. Zhou, D. Xing, Z. Ou, B. Wu, D. E. Resasco and W. R. Chen, J. Biomed. Opt., 2009, 14, 021009-0210010.

15 L. R. Hirsch, A. M. Gobin, A. R. Lowery, F. Tam, R. A. Drezek, N. J. Halas and J. L. West, Ann. Biomed. Eng., 2006, 34, 15-22.

16 H. Park, J. Yang, S. Seo, K. Kim, J. Suh, D. Kim, S. Haam and K.-H. Yoo, Small, 2008, 4, 192-196.

17 H. Ke, J. Wang, S. Tong, Y. Jin, S. Wang, E. Qu, G. Bao and Z. Dai, Theranostics, 2013, 4, 12-23.

18 S. M. Lee, H. Park, J. W. Choi, Y. N. Park, C. O. Yun and K. H. Yoo, Angew. Chem., Int. Ed., 2011, 50, 7581-7586.
19 A. Topete, M. Alatorre-Meda, E. M. Villar-Alvarez, S. CarregalRomero, S. Barbosa, W. J. Parak, P. Taboada and V. Mosquera, Adv. Healthc. Mater., 2014, 3, 1309-1325.

20 T. Kawano, Y. Niidome, T. Mori, Y. Katayama and T. Niidome, Bioconjugate Chem., 2009, 20, 209-212.

21 J. Ramos, A. Imaz and J. Forcada, Polym. Chem., 2012, 3, 852856.

22 N. S. Rejinold, K. P. Chennazhi, S. V. Nair, H. Tamura and R. Jayakumar, Carbohydr. Polym., 2011, 83, 776-786.

23 S. Indulekha, P. Arunkumar, D. Bahadur and R. Srivastava, Mater. Sci. Eng., C, 2016, 62, 113-122.

24 A. K. Rengan, A. B. Bukhari, A. Pradhan, R. Malhotra, R. Banerjee, R. Srivastava and A. De, Nano Lett., 2015, 15, 842-848.

25 S. Sasidharan, D. Bahadur and R. Srivastava, ACS Appl. Mater. Interfaces, 2016, 8, 15889-15903.

26 N. S. Rejinold, K. P. Chennazhi, S. V. Nair, H. Tamura and R. Jayakumar, Carbohydr. Polym., 2011, 83, 776-786.

27 J. F. Hainfeld, L. Lin, D. N. Slatkin, F. Avraham Dilmanian, T. M. Vadas and H. M. Smilowitz, Nanomedicine, 2014, 1-10. 28 F.-P. Gao, Y.-X. Lin, L.-L. Li, Y. Liu, U. Mayerhöffer, P. Spenst, J.-G. Su, J.-Y. Li, F. Würthner and H. Wang, Biomaterials, 2014, 35, 1004-1014.

29 D. P. O'Neal, L. R. Hirsch, N. J. Halas, J. D. Payne and J. L. West, Cancer Lett., 2004, 209, 171-176.

30 D. K. Roper, W. Ahn and M. Hoepfner, J. Phys. Chem. C. Nanomater Interfaces, 2007, 111, 3636-3641.

31 W. Zhang, Z. Guo, D. Huang, Z. Liu, X. Guo and H. Zhong, Biomaterials, 2011, 32, 8555-8561.

32 H. Park, J. Yang, J. Lee, S. Haam, I.-H. Choi and K.-H. Yoo, ACS Nano, 2009, 3, 2919-2926.

33 J. You, G. Zhang and C. Li, ACS Nano, 2010, 4, 1033-1041.

34 R. Guo, L. Zhang, H. Qian, R. Li, X. Jiang and B. Liu, Langmuir, 2010, 26, 5428-5434.

35 X. Li, M. Takashima, E. Yuba, A. Harada and K. Kono, Biomaterials, 2014, 35, 6576-6584.

36 B. L. Fay, J. R. Melamed and E. S. Day, Int. J. Nanomed., 2015, 10, 6931-6941.

37 A. N. Bashkatov, E. A. Genina, V. I. Kochubey and V. V Tuchin, J. Phys. D: Appl. Phys., 2005, 38, 2543-2555.

38 T. B. Huff, L. Tong, Y. Zhao, M. N. Hansen, J.-X. Cheng and A. Wei, Nanomedicine, 2007, 2, 125-132.

39 S. Mukundan, K. B. Ghaghada, C. T. Badea, C.-Y. Kao, L. W. Hedlund, J. M. Provenzale, G. A. Johnson, E. Chen, R. V. Bellamkonda and A. Annapragada, Am. J. Roentgenol., 2006, 186, 300-307.

40 C. Alric, J. Taleb, G. Le Duc, C. Mandon, C. Billotey, A. Le Meur-Herland, T. Brochard, F. Vocanson, M. Janier, P. Perriat, S. Roux and O. Tillement, J. Am. Chem. Soc., 2008, 130, 5908-5915.

41 W. Bottinor, P. Polkampally and I. Jovin, Int. J. Angiol., 2013, 22, 149-154.

42 T. Reuveni, M. Motiei, Z. Romman, A. Popovtzer and R. Popovtzer, Int. J. Nanomed., 2011, 6, 2859-2864.

43 V. Kattumuri, K. Katti, S. Bhaskaran, E. Boote, S. Casteel, G. Fent, D. Robertson, M. Chandrasekhar, R. Kannan and K. Katti, Small, 2007, 3, 333-341. 